\title{
A Study on Thermal Performance of a Novel All-Glass Evacuated Tube Solar Collector Manifold Header with an Inserted Tube
}

\author{
Jichun Yang, ${ }^{1}$ Qingyang Jiang, ${ }^{1}$ Jingxin Hou, ${ }^{1}$ and Chenglong Luo ${ }^{2}$ \\ ${ }^{1}$ College of Civil Engineering and Architecture, Jiaxing University, 56 Yuexiu South Road, Jiaxing, Zhejiang 314001, China \\ ${ }^{2}$ Institute of Energy, Jiangxi Academy of Sciences, Nanchang, Jiangxi 330096, China
}

Correspondence should be addressed to Jichun Yang; jchyang2004@126.com

Received 4 February 2015; Revised 19 April 2015; Accepted 20 April 2015

Academic Editor: Yuehong Su

Copyright (c) 2015 Jichun Yang et al. This is an open access article distributed under the Creative Commons Attribution License, which permits unrestricted use, distribution, and reproduction in any medium, provided the original work is properly cited.

A novel all-glass evacuated tube collector manifold header with an inserted tube is proposed in this paper which makes water in allglass evacuated solar collector tube be forced circulated to improve the performance of solar collector. And a dynamic numerical model was presented for the novel all-glass evacuated tube collector manifold header water heater system. Also, a test rig was built for model validation and comparison with traditional all-glass evacuated tube collector. The experiment results show that the efficiency of solar water heater with a novel collector manifold header is higher than traditional all-glass evacuated tube collector by about $5 \%$ and the heat transfer model of water heater system is valid. Based on the model, the relationship between the average temperature of water tank and inserted tube diameter (water mass flow) has been studied. The results show that the optimized diameter of inserted tube is $32 \mathrm{~mm}$ for the inner glass with the diameter of $47 \mathrm{~mm}$ and the water flow mass should be less than $1.6 \mathrm{Kg} / \mathrm{s}$.

\section{Introduction}

Hughes et al. [1] showed that the penalties for evacuated tube collectors with UL of about $0.8 \mathrm{~W} / \mathrm{m}^{2} \cdot{ }^{\circ} \mathrm{C}$ were substantially less than for flat-plate collectors with $\mathrm{UL}=4.0 \mathrm{~W} / \mathrm{m}^{2}{ }^{\circ} \mathrm{C}$; the collectors with low UL are not nearly as sensitive to temperature as those with UL representative of those of flatplate air heaters. So, compared to flat-plate collectors, allglass evacuated tube collectors have high thermal efficiency. It has better performance than flat-plate collectors under high temperature operation because of reduced convection heat loss due to the vacuum envelope around the absorber surface. The capacity of energy production of all-glass evacuated tube in China in 2010 was estimated to be 46 million $\mathrm{m}^{2}$ per year [2] and this was also widely used in many fields such as industrial hot water, HVAC, drying, agriculture, aquiculture, and seawater desalination. A lot of experimental and theoretical researches on traditional all-glass evacuated tube collectors have been undertaken by many scholars [3-9].
A traditional all-glass evacuated tube collector typically consists of 15-40 flooded single-ended tubes in direct connection to a horizontal tank or collector manifold header. The cycling process inside the evacuated tubes is always natural convective whether solar water heating circulation system is natural convective or forced. Obviously, the performance of all-glass evacuated tube collector will be better if water in evacuated tube is forced-circulated because all the water will be replaced for every cycle.

In this paper, a novel all-glass evacuated tube solar collector manifold header with a inserted tube is proposed, which makes water in all-glass evacuated solar collector tube be forced-circulated. A dynamic numerical model is presented for novel collector manifold header water heater system and a test rig is also built for model validation and comparison with traditional all-glass evacuated tube collector. Based on the model, the relationship between the average temperature of water tank and inserted tube diameter (water mass flow) has been studied. This work provides some information and 


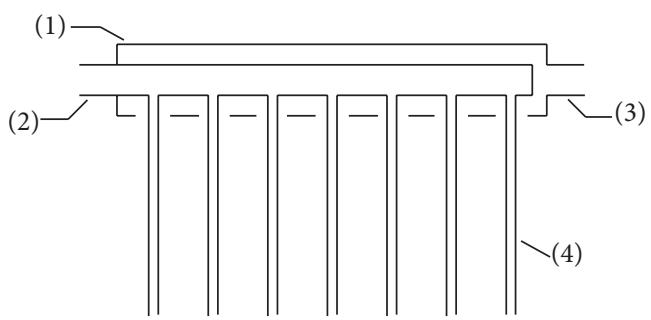

(1) Water tank connecting with evacuated solar collector tubes

(2) Connecting tube 1 (inlet)

(3) Connecting tube 2 (outlet)

(4) Inserted tubes

FIGURE 1: Schematic diagram of a novel all-glass evacuated tube solar collector manifold header with inserted tubes.

designs for all-glass evacuated tube collector with a novel collector manifold header.

\section{Manifold Header Configuration and Operating Mode}

2.1. Manifold Header Configurations. The schematic diagram of the novel all-glass evacuated tube solar collector manifold header with inserted tubes is shown in Figure 1. A novel manifold header consists of water tank (1), the first connecting tube (2), the second connecting tube (3), and a series of inserted tubes (4). Water tank is thermal insulated and with the cross section of circle or square. The diameter (or length) of the cross section is about $20-40 \mathrm{~mm}$. There are round orifices in water tank which are connected to all-glass evacuated tubes. Water tank connects with the first connecting tube and the second connecting tube and the joints are both sealed. Connection between the first connecting tube and the inserted tube is threaded or bonded by high-strength heat resistant cement. The material of connecting tube and inserted tube is stainless steel or plastic which has good heat resistance.

2.2. Operating Mode. The application of the novel all-glass evacuated tube solar collector manifold header with inserted tubes is shown in Figure 2. The inserted tubes extend into the all-glass evacuated tube and joint of the first connecting tube and the second connecting tube of the previous manifold header. Cooling water from the previous manifold header flows into the first connecting tube and is forced into allglass evacuated tube through the inserted tubes. Then the water flow is heated by solar radiation and guided to water tank through the gap between inserted tubes and all-glass evacuated tube.

\section{Experiment of Solar Water Heating System}

A test rig is built according to the schematic structure which is shown in Figure 3. The test rig has two subsystems of solar water heating system. Each subsystem is composed of a solar water collector (one with a novel collector manifold header

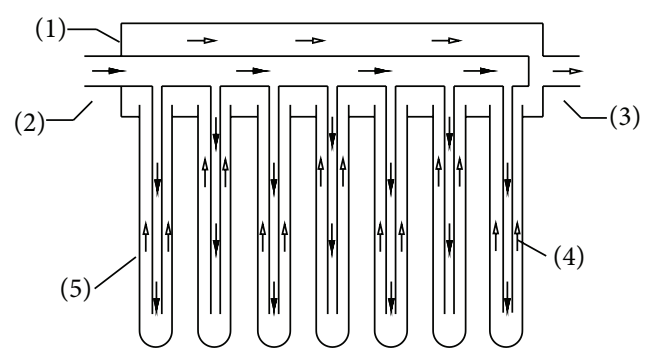

(1) Water tank connecting with evacuated solar collector tubes

(2) Connecting tube 1

(3) Connecting tube 2

(4) Inserted tubes

(5) All-glass evacuated solar collector tube

$\rightarrow$ Cooling water

$\longrightarrow$ Hot water

FIGURE 2: Water flow direction in all-glass evacuated tube collectors with a novel collector manifold header.

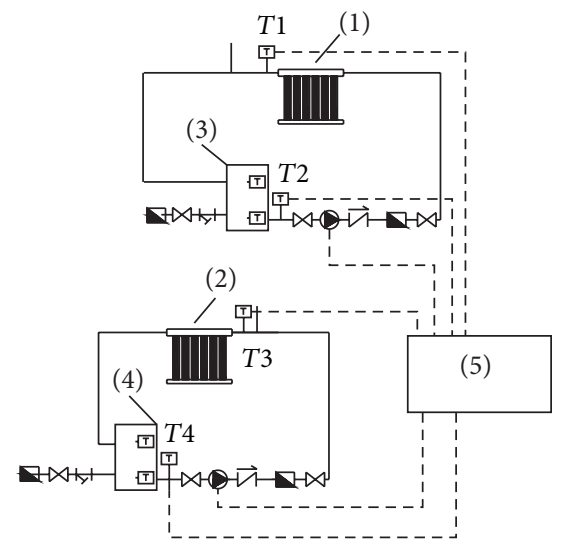

(1) Novel evacuated tubes solar collector

(2) Traditional evacuated tubes solar collector

甲 Temperature sensor

(3) Water tank 1

(4) Water tank 2

(5) Control system

$\bowtie$ Valve

$\vec{n}$ Check valve

Water meter

(1) Water pump

$\rightarrow \rightarrow$ Y type filter

FIGURE 3: Overview of test rig of a novel all-glass evacuated tube solar collector manifold header with an inserted tube.

and the other is ordinary all-glass evacuated tube collector), water tanks, water pumps, and so forth. The two subsystems are nearly the same except for solar water collector; collector with a novel collector manifold header consists of evacuated tubes and a novel manifold header which interconnects the tubes and circulates heat transfer fluid. For each subsystem of solar water heating system, T-type temperature sensors (Ttype temperature's testing range is $-40^{\circ} \mathrm{C}-200^{\circ} \mathrm{C}$; accuracy is $\pm 0.2^{\circ} \mathrm{C}$ ) are set to measure the temperature at bottom (1 sensor) and inner (3 sensors) of water tank, ambient temperature (1 sensor), and water temperature at outlet of solar collector (1 sensor). Solar radiation (pyranometers' testing range is $0-2000 \mathrm{w} / \mathrm{m}^{2}$; accuracy is less than $2 \%$ ) and water mass flow (flowmeter's testing range is $0.6-6 \mathrm{~m}^{3} / \mathrm{h}$; 


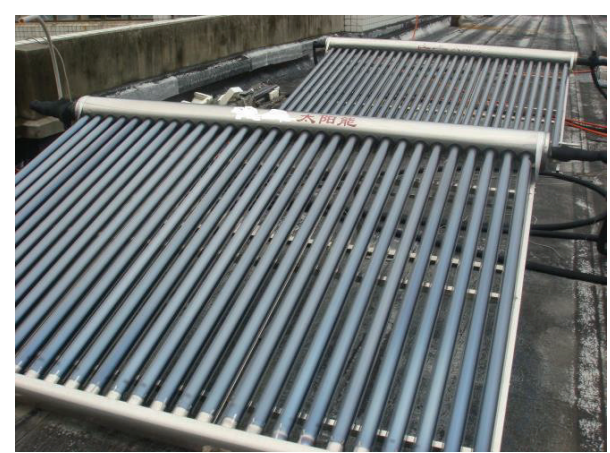

FIGURE 4: The picture of solar water heater.

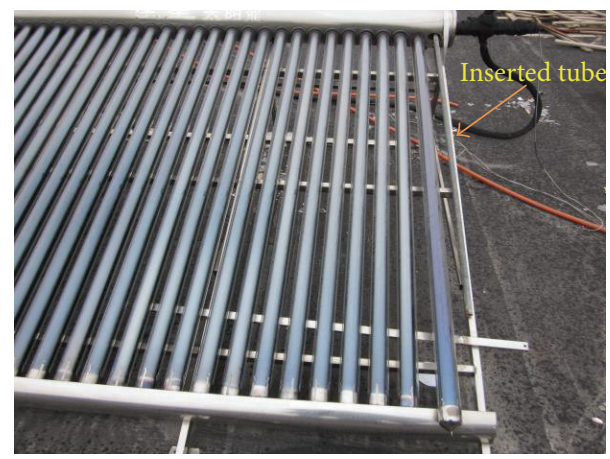

FIGURE 5: The picture of solar water heater with a novel collector manifold header.

accuracy is $\pm 0.5 \%$ ) of this system are also measured. All the data are recorded every minute by a Keithley 2700 data logger. The pump is controlled by a differential thermostat that turns on the pump when the temperature at the top header is higher than the temperature of the water in the bottom of the tank by a sufficient margin.

Solar collector in each subsystem is with the area of $2550 \mathrm{~mm} \times 1950 \mathrm{~mm}$ and consists of 30 all-glass evacuated tubes, which are $\phi 58 \times 1800$. The aperture area of each solar collector is $4.97 \mathrm{~m}^{2}$; the diameter of each inserted tube is $18 \mathrm{~mm}$ and its length is $1950 \mathrm{~mm}$; the volume of water tank is $300 \mathrm{~L}$. Figure 4 shows the picture of solar water heater and Figure 5 shows the picture of solar water heater with a novel collector manifold header.

This experimental research is focused on the heat storage performance of each subsystem of solar water heating system. A test had been performed in Jiaxing at August 9, 2013. The test method is according to the test methods for the thermal performance of solar collectors (GB/T 4271-2007). The test was started at $8 \mathrm{am}$ and finished at $4 \mathrm{pm}$ with the water flow velocity of $0.2 \mathrm{~m} / \mathrm{s}$. Figures 6 and 7 show the experimental data of ambient air temperature and radiation variation during the test period. Figure 7 and Table 1 show the experimental results of temperature variation in the water tank during the test period. It can be seen from Figure 8 that temperature of water tank 1 is higher than water tank 2; the largest difference between them is about $4^{\circ} \mathrm{C}$. From Table 1 we can see that the efficiencies of solar water heater with a novel

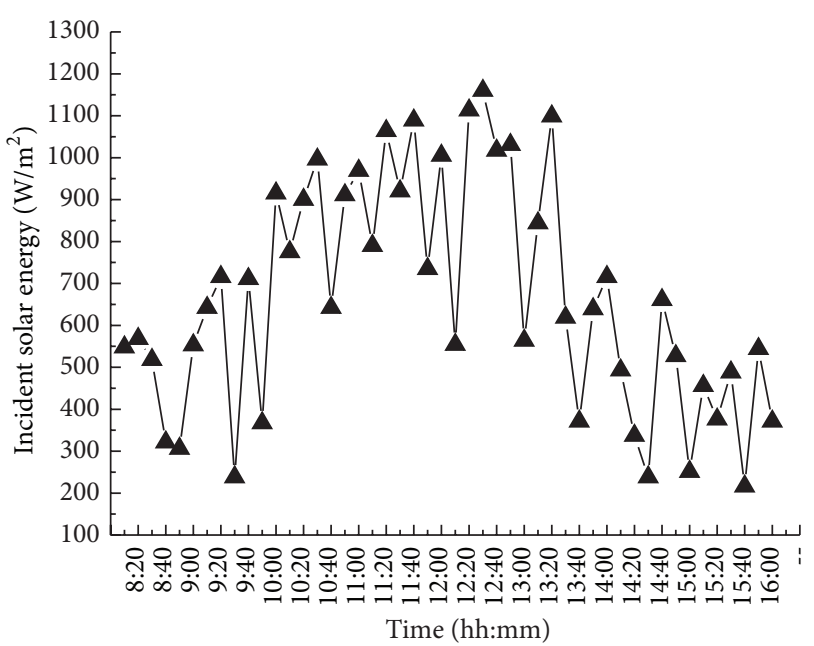

FIGURE 6: Incident solar energy versus testing time.

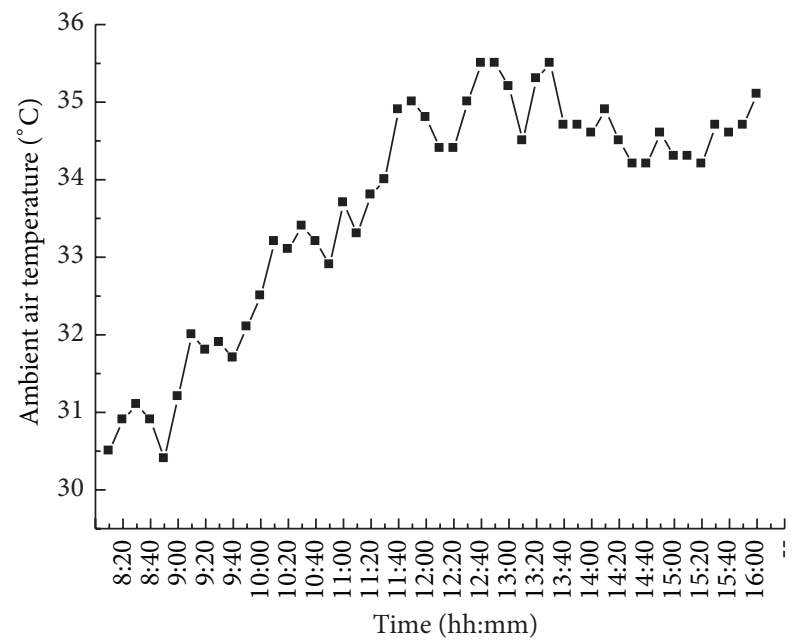

Figure 7: Ambient air temperature versus testing time.

TABLE 1: Comparison of the two solar water heater's heat performance.

\begin{tabular}{lcc}
\hline & $\begin{array}{c}\text { Novel solar } \\
\text { water heater }\end{array}$ & $\begin{array}{c}\text { Normal solar } \\
\text { water heater }\end{array}$ \\
\hline $\begin{array}{l}\text { Heat storage in water tank (kJ) } \\
\text { Solar irradiance on solar } \\
\text { collector (kJ) }\end{array}$ & 57396.42 & 52800.92 \\
Efficiency of solar collector (\%) & 95678.66 & 95678.66 \\
\hline
\end{tabular}

collector manifold header and the normal solar water heater are $59.99 \%$ and $55.19 \%$, respectively. It is because that water in all-glass evacuated solar collector tube is forced-circulated for novel solar water heater and the normal solar water heater is under natural convection process. 


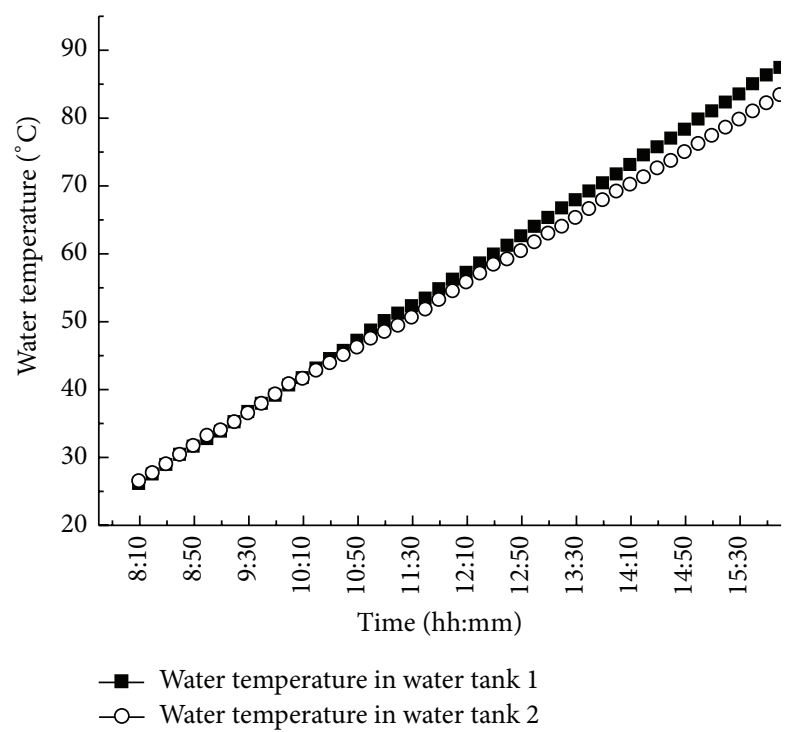

FIGURE 8: Water temperature in water tank 1 and water tank 2 versus testing time.

\section{Numerical Model and Model Validation of Solar Water Heating System}

The schematic of the proposed all-glass evacuated tube collectors with a novel collector manifold header is shown in Figure 2. The all-glass evacuated tube collector consisted of water tank connecting with evacuated solar collector tubes (1), connecting tube 1 (2), connecting tube 2 (3), inserted tubes (4), and all-glass evacuated solar collector tube. The heat transfer mechanism of novel collector is seen in Figure 9. Water between inner glass and inserted tube is heated by solar radiation, which then rises along the top of the tube to the collector tube and is replaced by colder water from connecting tube 1 entering into the bottom of the inserted tubes.

To analyze its energy input and output, the heat balance equation of water heating system with novel collector manifold header had been created. To build the heat transfer model, the following assumptions have been made:

(1) properties are independent of temperature;

(2) ambient temperatures related to heat loss at front and back sides are the same;

(3) dust and dirt on the collector are negligible;

(4) radiation absorbed by the back of collector is negligible;

(5) shadows from one pipe to the next are neglected;

(6) pump power of water heater system is negligible;

(7) heat loss between the collector and water tank is negligible;

(8) the stratification of hot water in tank is negligible;

(9) the heat transfer between inner water and outside water of inserted tubes is negligible.
4.1. Outer Glass Tube. Consider

$$
\begin{aligned}
\rho_{\mathrm{go}} C_{\mathrm{go}} \frac{\partial \overline{T_{\mathrm{go}}}}{\partial t} & =\lambda_{\mathrm{go}} \frac{\partial^{2} \overline{T_{\mathrm{go}}}}{\partial x^{2}}+S_{\text {solar }}, \\
-\left.\lambda_{\mathrm{go}} \frac{\partial \overline{T_{\mathrm{go}}}}{\partial x}\right|_{x=0} & =h_{a, \mathrm{go}}\left(T_{a}-\overline{T_{\mathrm{go}}}\right), \\
-\left.\lambda_{\mathrm{go}} \frac{\partial T_{\mathrm{go}}}{\partial x}\right|_{x=d_{\mathrm{go}}} & =h_{r, p, \mathrm{go}}\left(\overline{T_{\mathrm{gi}}}-\overline{T_{\mathrm{go}}}\right),
\end{aligned}
$$

where $\overline{T_{\mathrm{go}}}, \lambda_{\mathrm{go}}, \rho_{\mathrm{go}}, c_{\mathrm{go}}$, and $d_{\mathrm{go}}$ are temperature, thermal conductivity, density, specific heat capacity, and depth of outer tube glass, respectively. $T_{a}, \overline{T_{\mathrm{gi}}}$ are temperature of ambient temperature and inner tube glass, respectively. $h_{a, \text { go }}$ is heat transfer coefficient between outer tube glass and ambient air. $h_{r, p \text {,go }}$ is radiative heat transfer coefficient between outer tube glass and inner tube glass. $S_{\text {solar }}$ is the thermal source of outer glass which absorbs the solar radiation.

\subsection{Inner Glass Tube. Consider}

$$
\begin{aligned}
\rho_{\mathrm{gi}} C_{\mathrm{gi}} \frac{\partial \overline{T_{\mathrm{gi}}}}{\partial t} & =\lambda_{\mathrm{gi}} \frac{\partial^{2} \overline{T_{\mathrm{gi}}}}{\partial x^{2}}+S_{\text {solarl }}, \\
-\left.\lambda_{\mathrm{gi}} \frac{\partial \overline{T_{\mathrm{gi}}}}{\partial x}\right|_{x=0} & =h_{w, \mathrm{gi}}\left(T_{w}-\overline{T_{\mathrm{gi}}}\right), \\
-\left.\lambda_{\mathrm{gi}} \frac{\partial \overline{T_{\mathrm{gi}}}}{\partial x}\right|_{x=d_{\mathrm{gi}}} & =h_{r, p, \mathrm{go}}\left(\overline{T_{\mathrm{gi}}}-\overline{T_{\mathrm{go}}}\right),
\end{aligned}
$$

where $\overline{T_{\mathrm{gi}}}, \lambda_{\mathrm{gi}}, \rho_{\mathrm{gi}}, c_{\mathrm{gi}}$, and $d_{\mathrm{gi}}$ are temperature, thermal conductivity, density, specific heat capacity, and depth of inner tube glass, respectively. $T_{w}, \overline{T_{\mathrm{go}}}$ are temperature of water and outer tube glass, respectively. $h_{w \text {,gi }}$ is heat transfer coefficient between inner tube glass and water. $h_{r, p \text {,go }}$ is radiative heat transfer coefficient between outer tube glass and inner tube glass. $S_{\text {solar } 1}$ is the thermal source of inner glass which absorbs the solar radiation.

4.3. Water Flow in Inner Tube Glass. Heat exchange exists along the water flow direction through the convective heat flow:

$$
\begin{aligned}
c_{f} \rho_{f} A_{f} \frac{\partial T_{f}}{\partial t}= & \left(h_{f} l_{\text {tube }}\right)\left(\overline{T_{\text {gi }}}-T_{f}\right)-A_{f} u_{f} \rho_{f} \mathcal{c}_{f} \frac{\partial T_{f}}{\partial x} \\
& +A_{f} \lambda_{f} \frac{\partial^{2} T_{f}}{\partial x^{2}},
\end{aligned}
$$

where $T_{f}$ is the temperature of water flow, $\rho_{f}, c_{f}$, and $\lambda_{f}$ are density, specific heat capacity, and heat conductivity of water, respectively; $A_{f}$ is cross section area of water in the inner tube; $h_{f}$ is heat convective coefficient between water flow and inner tube glass; $u_{f}$ is the mean water flow velocity in the inner tube glass; and $\overline{T_{\text {gi }}}$ is the temperature of inner tube glass; $l_{\text {tube }}$ is the perimeter of cross section of inner tube glass. 


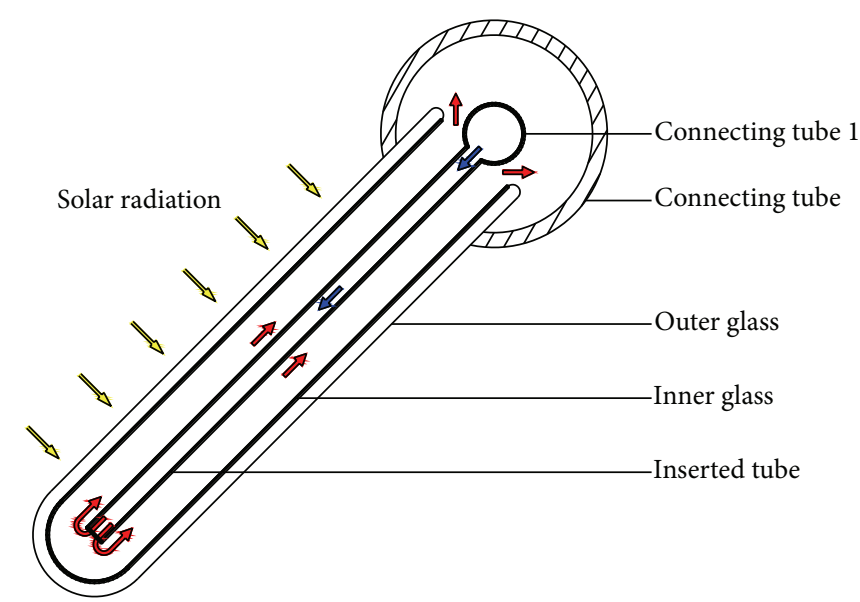

FIGURE 9: The heat transfer mechanism of novel collector.

4.4. Water Tank. An energy balance on the unstratified tank is

$$
\left(m C_{p}\right)_{s} \frac{d T_{s}}{d t}=Q_{u}-L_{s}-(U A)_{s}\left(T_{s}-T_{a}\right),
$$

where $Q_{u}$ and $L_{s}$ are rates of addition or removal of energy from the collector and to the load and $T_{a}$ is the ambient temperature for the tank; $m$ is the water flow mass; $C_{p}$ is specific heat capacity; $T_{s}$ is the temperature of water in tank; $U$ is the heat coefficient between water tank and ambient temperature; $A$ is the area of water tank surface.

4.5. Heat Transfer Coefficient. Heat transfer coefficient between outer glass tube surface and outdoor environment can be calculated by (5) [10]; here $u$ means wind velocity of outdoor environment:

$$
h_{\mathrm{wo}}=5.6+3.8 u \text {. }
$$

Heat transfer coefficient between inner glass surface and water flow can be calculated by (6) [11] and (7) [12]. Heat transfer coefficient is calculated by (6) when $\operatorname{Re}_{f}=2300 \sim$ $10^{6}$ and is calculated by (7) when $\operatorname{Re}_{f} \leq 2300$. Here Re is the Reynolds number; $d$ is the diameter of inner glass tube; $l$ is the length of inner glass tube; $\mathrm{pr}_{f}$ is the water Prandtl number for water temperature; $\mathrm{pr}_{w}$ is the water Prandtl number for inner glass tube temperature; consider

$$
\begin{aligned}
\mathrm{Nu}_{f} & =\frac{(f / 8)(\mathrm{Re}-1000) \mathrm{pr}_{f}}{1+12.7 \sqrt{f / 8}\left(\mathrm{pr}_{f}^{2 / 3}-1\right)}\left[1+\left(\frac{d}{l}\right)^{2 / 3}\right] c_{t} \\
c_{t} & =\left(\frac{\mathrm{pr}_{f}}{\mathrm{pr}_{w}}\right)^{0.01}, \frac{\mathrm{pr}_{f}}{\mathrm{pr}_{w}}=0.05 \sim 20 \\
f & =(1.82 \operatorname{lgRe}-1.64)^{-2} \\
\overline{\mathrm{Nu}_{f}} & =3.66+\frac{0.065(d / l) \operatorname{Re} \operatorname{Pr}_{f}}{1+0.04\left[(d / l) \operatorname{Re} \operatorname{Pr}_{f}\right]^{2 / 3}} .
\end{aligned}
$$

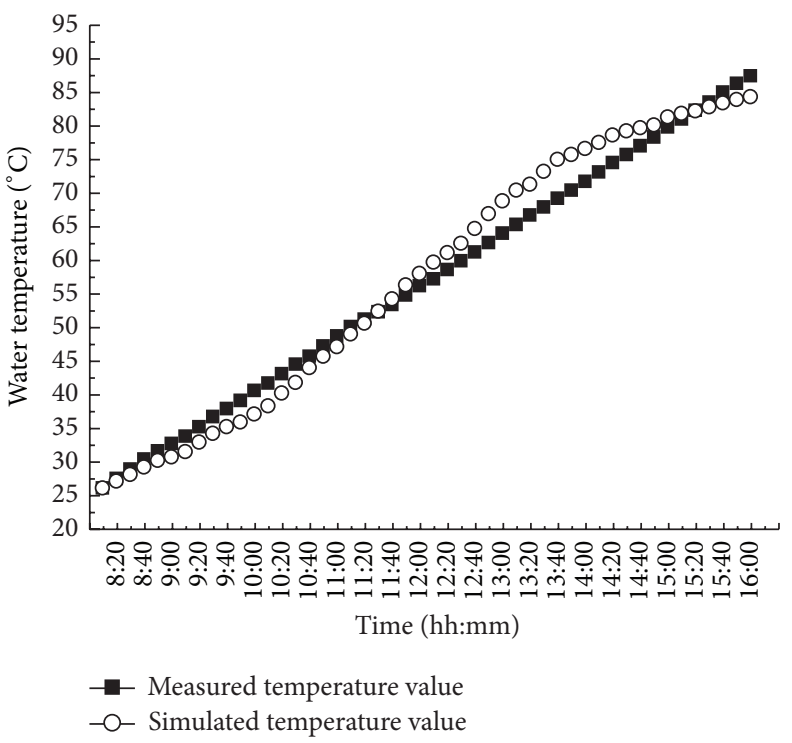

FIGURE 10: Measured water temperature value and simulated water temperature value versus testing time.

The simulation of mean water tank temperature based on the numerical model described in Section 4 is also carried out under the same condition as the experiment and the simulation results are given along with the experimental data. Figure 10 shows a good agreement between the measured and simulated results and the difference between them is less than $1.50^{\circ} \mathrm{C}$. So the heat transfer model of water heater system is valid.

\section{Performance Analysis of All-Glass Evacuated Tube Collector with a Novel Manifold Header}

After the numerical model had been verified by the experimental data of the test rig, the simulation was executed to study the thermal characteristic of all-glass evacuated tube 
collector with a novel collector manifold header and intended to find the optimized structural parameters and operated parameters of novel collector manifold header.

5.1. Condition Setting and Optimization Method. All-glass evacuated tube collector with a novel collector manifold header will lead the water flow to the bottom of evacuated tube by forced convection. So the size of inserted tubes and the mass flow of water have a significant impact on the thermal characteristic of all-glass evacuated tube collector with a novel collector manifold header. Performance analysis had been performed in order to acquire and achieve optimized diameter parameters of inserted tube and optimized mass flow of water. The following condition settings are made for the simulation:

(1) the structural parameters of all-glass evacuated solar collector are the same as the test rig except for the diameter of inserted tube;

(2) the volume of water tank is $300 \mathrm{~L}$;

(3) meteorological data is the same as Figures 6 and 7 for simulation;

(4) the system operates between 8 am and $4 \mathrm{pm}$;

(5) initial water tank temperature is $25^{\circ} \mathrm{C}$.

Optimization analysis method and procedure for the diameter and water mass flow are as follows:

(1) For a given forced water mass flow, obtain the mean temperature of water tank for the different diameter of inserted tube.

(2) For a given diameter of inserted tube, obtain the mean temperature of water tank for the different forced water mass flow.

(3) According to the results of the above, obtain the optimized diameter of inserted tube and water mass flow.

\subsection{Results and Discussions}

5.2.1. Mean Water Tank Temperature Variation with the Diameter of Inserted Tube for a Given Water Mass Flow. When the water mass flow keeps constant, Figure 11 shows the mean water tank temperature variation with the diameter of inserted tubes. There are three curves which represent water mass flow of $0.45 \mathrm{Kg} / \mathrm{s}, 0.6 \mathrm{Kg} / \mathrm{s}$, and $0.8 \mathrm{Kg} / \mathrm{s}$, respectively; the results indicate the final mean tank temperature increases with the diameter of inserted tube become larger and then the final mean temperature of the water tank decreases when the diameter of inserted tube reaches $32 \mathrm{~mm}$. It is because that heat convective coefficient between water flow and inner tube glass is correlated with the Reynolds number (Re) and Re is determined by water flow velocity and equivalent diameter $\left(d_{e}\right)$ (equivalent diameter is the channel between the inserted tube and inner glass), namely, $\operatorname{Re}=u d_{e} / \nu$, there is a maximum heat convective coefficient at a given water mass flow. In addition, it can be seen that the final

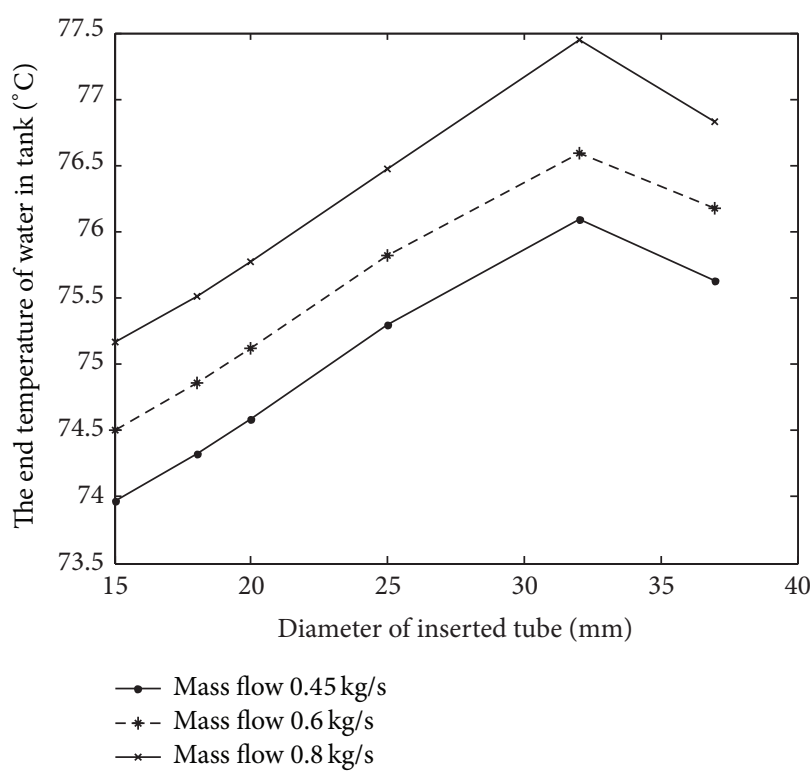

FIGURE 11: Water tank temperature versus inserted tube outer diameter under different mass flow rate.

mean water tank temperature increase with the water mass flow becomes larger. The highest final mean water tank temperature increases from $76.1^{\circ} \mathrm{C}$ to $77.5^{\circ} \mathrm{C}$.

5.2.2. Mean Water Tank Temperature Variation with the Water Flow Mass for a Given Diameter of Inserted Tube. When diameter of inserted tubes keeps constant, Figure 12 shows the mean water tank temperature variation with the water flow mass. There are three curves which represent diameter of inserted tube of $20 \mathrm{~mm}, 25 \mathrm{~mm}$, and $32 \mathrm{~mm}$, respectively. Results indicate the final mean tank temperature increases with the water flow mass become larger. And the final mean temperature of the water tank will be the same when the water flow mass reaches $1.6 \mathrm{Kg} / \mathrm{s}$. First, heat convective coefficient between water flow and inner tube glass will become larger with the water flow mass increasing and it makes the water tank collect more energy. On the other hand, there is heat loss to ambient air at any condition; the heat loss will become larger when the water flow temperature becomes higher. So the final mean water tank temperature will not increase at certain situation when the water flow mass is increasing. In addition, the final mean tank temperature increases with the diameter of inserted tube become larger at a given water mass flow; it is agreed with the results of 3.2.1.

From the analysis above, it can be concluded that the optimized diameter of inserted tube is $32 \mathrm{~mm}$ for that inner glass with the diameter of $47 \mathrm{~mm}$ and the water flow mass should be less than $1.6 \mathrm{Kg} / \mathrm{s}$.

\section{Conclusion}

To improve the performance of traditional all-glass evacuated tube collector, a novel collector manifold header with an inserted tube is proposed in this paper and a dynamic 


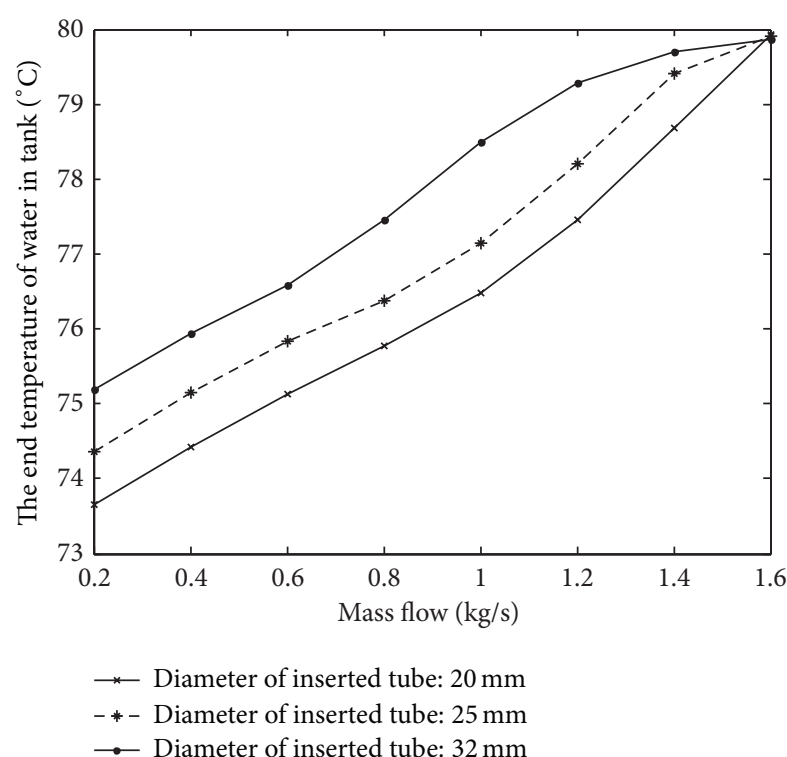

FIGURE 12: Water tank temperature versus mass flow rate under different inserted tube outer diameter.

numerical model was presented for novel collector manifold header water heater system. Also, a test rig was built for model validation and comparison with traditional all-glass evacuated tube collector. Experiment results show the efficiency of solar water heater with a novel collector manifold header which is higher than traditional all-glass evacuated tube collector by about $5 \%$ and the heat transfer model of water heater system is valid. Based on the valid model, the relationship between the water tank average temperature and inserted tube diameter (water mass flow) is studied. Results show the optimized diameter of inserted tube is $32 \mathrm{~mm}$ for the diameter of inner glass is $47 \mathrm{~mm}$ and the water flow mass should be smaller than $1.6 \mathrm{Kg} / \mathrm{s}$. This work can provide some information and designs for all-glass evacuated tube collector with a novel collector manifold header.

There are a lot of simplified assumptions in this study. So further work need to study in the future that the pressures drop across a solar collector is very useful parameter to assess for the performance of a solar thermal collector, so pressure drop should be considered and assumptions (6) should be reconsidered to study relationship between the pump power and the solar collector efficiency.

\section{Conflict of Interests}

The authors declare that there is no conflict of interests regarding the publication of this paper.

\section{Acknowledgments}

The work described in this paper was supported by the National Science Foundation of China (NSFC), Project no. 51366004, the National Science Foundation of China (NSFC), Project no. 51408278, and The "Twelfth Five-Year" Key Disciplines in the Universities of Zhejiang Province, and Discipline of Building Energy Efficiency Technology (Department of Education of Zhejiang Province Office Document [2012] no. $80)$.

\section{References}

[1] P. J. Hughes, J. A. Duffie, and W. A. Beckman, "Simulation study of several solar heating systems with off-peak auxiliary," Solar Energy, vol. 19, no. 3, pp. 317-319, 1977.

[2] J. Bao and Z. An, "Rewable energy source: review 11th five year plan, look into 12th five year plan pt.3," Solar Energy (China), pp. 7-8, 2011.

[3] Y. Zhiqiang, G. L. Harding, and B. Window, "Water-in-glass manifolds for heat extraction from evacuated solar collector tubes," Solar Energy, vol. 32, no. 2, pp. 223-230, 1984.

[4] Z. Li, C. Chen, H. Luo, Y. Zhang, and Y. Xue, "All-glass vacuum tube collector heat transfer model used in forced-circulation solar water heating system," Solar Energy, vol. 84, no. 8, pp. 1413$1421,2010$.

[5] S. Arora, S. Chitkara, R. Udayakumar et al., "Thermal analysis of evacuated solar tube collectors," Journal of Petroleum and Gas Engineering, vol. 2, no. 4, pp. 74-82, 2011.

[6] T.-T. Chow, Z. Dong, L.-S. Chan, K.-F. Fong, and Y. Bai, "Performance evaluation of evacuated tube solar domestic hot water systems in Hong Kong," Energy and Buildings, vol. 43, no. 12, pp. 3467-3474, 2011.

[7] E. Dikmen, M. Ayaz, H. H. Ezen, E. U. Küçüksille, and A. Ş. Şahin, "Estimation and optimization of thermal performance of evacuated tube solar collector system," Heat and Mass Transfer, vol. 50, no. 5, pp. 711-719, 2014.

[8] S. Kumar, A. Dubey, and G. N. Tiwari, "A solar still augmented with an evacuated tube collector in forced mode," Desalination, vol. 347, pp. 15-24, 2014.

[9] P. Selvakumar, P. Somasundaram, and P. Thangavel, "Performance study on evacuated tube solar collector using therminol D-12 as heat transfer fluid coupled with parabolic trough," Energy Conversion and Management, vol. 85, pp. 505-510, 2014.

[10] K. S. Ong and C. C. Chow, "Performance of a solar chimney," Solar Energy, vol. 74, no. 1, pp. 1-17, 2003.

[11] F. P. Incropera, D. P. deWitt, T. L. Bergman, and A. S. Lavine, Fundamentals of Heat and Mass Transfer, John Wiley \& Sons, 2007.

[12] Y. Shabany, Heat Transfer: Thermal Management of Electronics, CRC Press, 2010. 

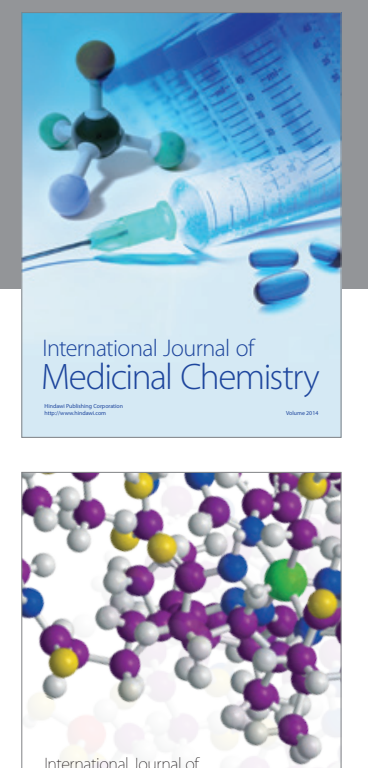

\section{Carbohydrate} Chemistry

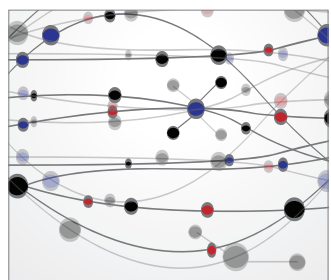

The Scientific World Journal
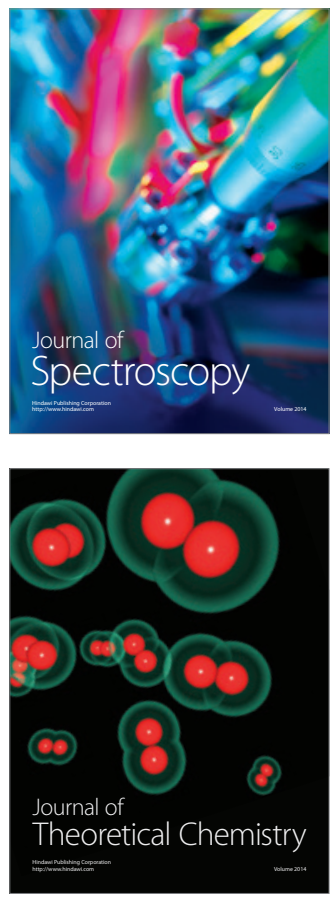
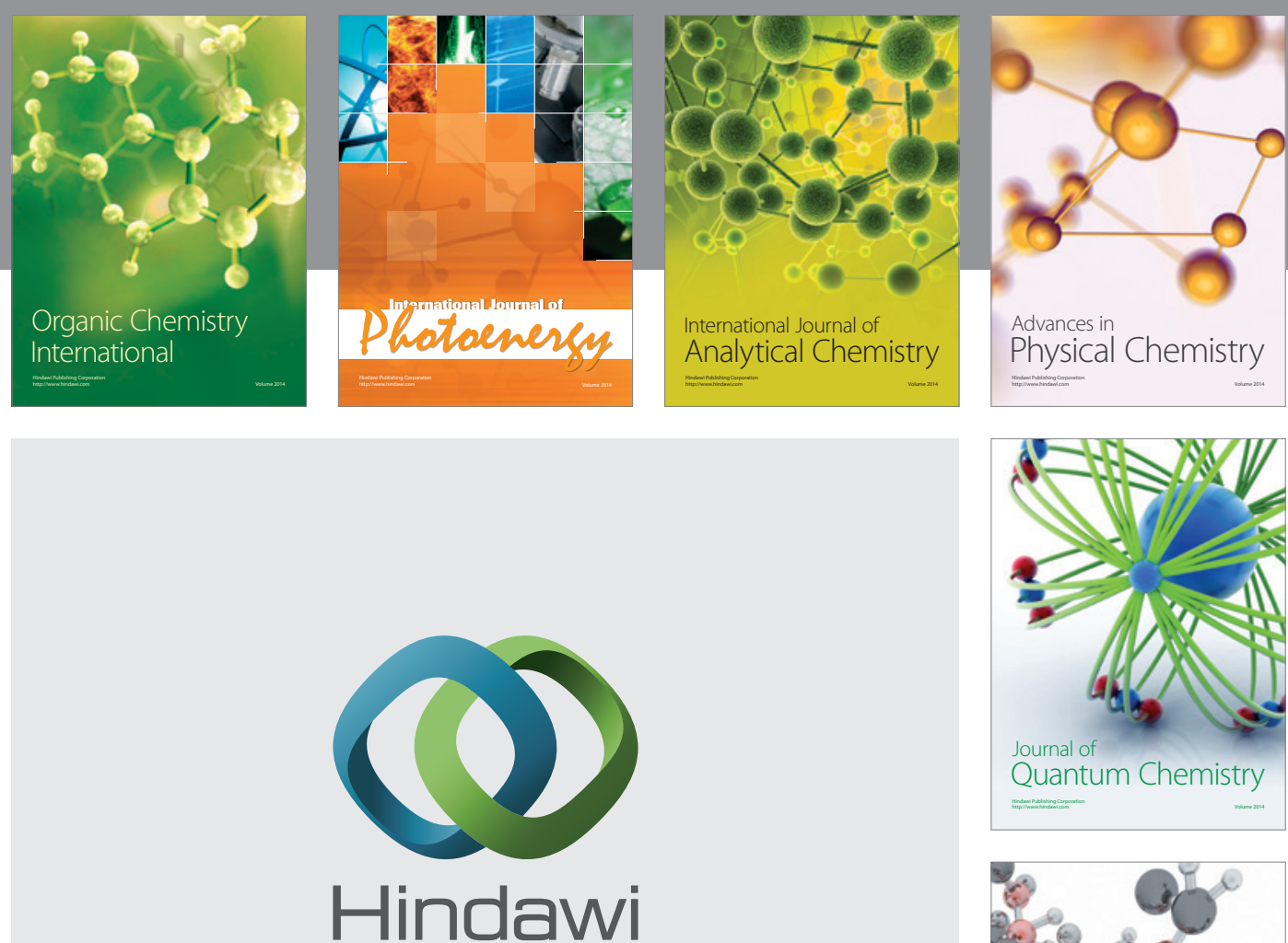

Submit your manuscripts at

http://www.hindawi.com

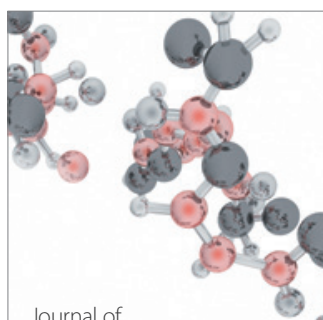

Analytical Methods

in Chemistry

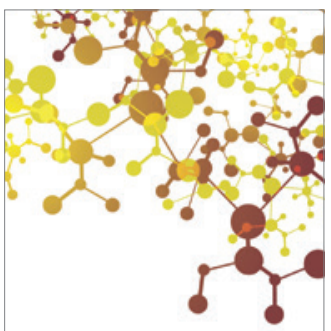

Journal of

Applied Chemistry

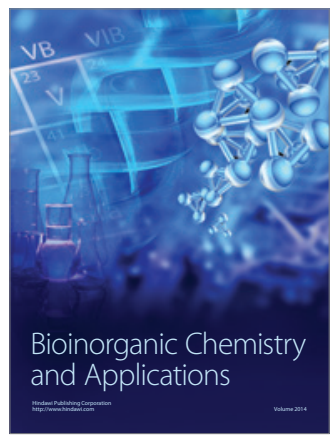

Inorganic Chemistry
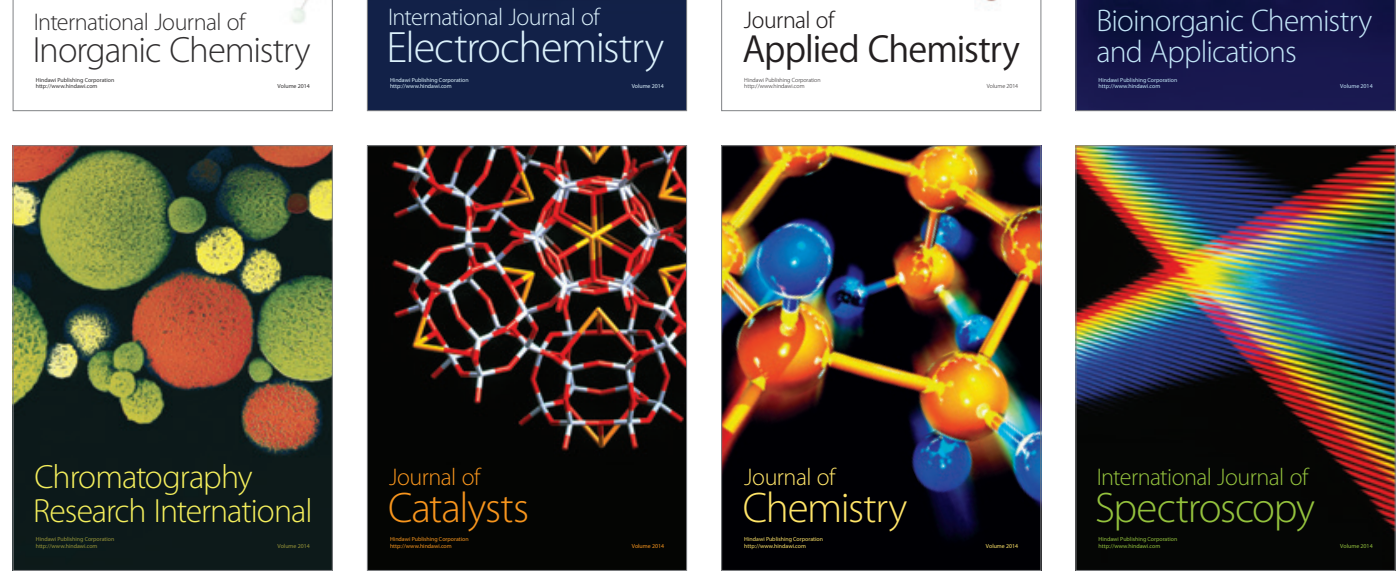